\title{
The Data Analysis of the Subway Noise Signal Based on MATLAB XIAO Qian
}

\author{
College of Information Engineering, Shenyang University, China.
}

\begin{abstract}
Keywords: noise signal, MATLAB, data analysis, subway station, subway carriage.
\end{abstract}
\begin{abstract}
As subway noise affected psychological, physiological and normal life of passengers and people along the track seriously, it becomes an important indicator of urban construction. In this paper, subway noise is analyzed by MATLAB for its efficient data analysis capabilities. The measured data is taken time domain and frequency domain analysis by Fourier function, and the noise intensity and frequency components can be calculated. The results can provide the recommendations and data base for future subway construction.
\end{abstract}

\section{Introduction}

With the development of urban rail transit, subway travel brought great convenience. However the subway noise generated by subway running can also bring great troubles to people. As early as 1979, Robert LOTZ and others published the paper about subway tunnel and station noise in the United States, and the mechanism of subway noise, sound level and noise control were analyzed briefly. In 2006, RobynR.M. and others made a preliminary study on the platform and the carriage of the New York subway [1, 2, 3]. Relatively speaking, the research on the subway noise was late in China [4, 5, 6]. Labor Health Research Institute of Ministry of Railway and the Beijing Underground Railway Technology Research Science took the subway platform in Beijing and Tianjin as the object of the research and made the measurements on the noise of the platform. Tan Shuying did a survey on platform noise and carriage interior of Guangzhou subway. The survey results show that metro's high-speed is the main source of environmental noise, and the subway platform noise is related to the radio frequency, radio volume, traffic and other factors.

Shenyang subway is the first metro plan in the northeast China. Currently, the research of Shenyang subway noise pollution has not been reported. For analyzing the impact of the early stages of Shenyang subway on passengers and people along the rail, time-domain and frequency domain analysis method are applied in this design to calculate the noise frequency and intensity. On this basis, the reasonable and effective proposal can be proposed.

\section{Subway noise}

\subsection{Noise generated in the process of subway}

Subway noise is generated by all kinds of noise, and affected by train running status and track device status. Among the many factors that produce noise, the proportion is different. The noise test data analysis of Japanese subway shows that: in the case of not taking any measures, the wheel-rail noise accounted for $78 \%$, the collector system noise accounted for $16 \%$, mechanical movement noise accounted for $4 \%$, and the airborne noise accounted for $2 \%$. As urban rail transit operation is intermittent, the run interval of subway or light rail trains is usually 2-6 minutes, driving in the morning 5:00 to night 11:00, and the noise level is proportional to the speed of the train. Studies have shown that when the train speed is less than $250 \mathrm{kmPh}$, railway noise is mainly to wheel-rail noise, and when the train speed is greater than $250 \mathrm{kmPh}$, railway noise is dominated by aerodynamic noise $[7,8]$.

\subsection{Subway noise factors}

The noise level of urban rail transit is related to system characteristics, and the location of the track is the determining factor affecting noise levels. The roadside noise level generated by the elevated railroad tracks is higher than the noise level of ground track. In addition, the speed of the train, the use of track types, the abrasions of wheel tread, the rough condition of track surface and 
other factors are all affecting the strength of the noise level. At the same time, soil and rock type, density, shear coefficient and loss factor, propagation distance, terrain condition, tunnel structure size and cross-sectional shape, thickness of the tunnel structure, tunnel depth, building type and structure, natural frequency of the floor, room size, etc. also have an impact on rail traffic noise.

\section{Subway noise analysis method}

\subsection{Time-domain analysis of noise}

Time-domain analysis method is the most common method used to analyze sound signal. Sound signal itself is time-domain signal, which directly use time domain waveforms of sound signal. Time-domain analysis is usually used for the basic parameters analysis, sound segmentation, preprocessing and large classification. The characteristic of time-domain analysis method are as follows: First, the sound signal is relatively intuitive and the physical meaning is clear. Second, it is simple to implement and the operational is less. Third, you can get some important parameters of sound. Fourth, it is simple by using general equipment such as oscilloscope $[9,10]$.

\subsection{Frequency-domain analysis of noise}

In frequency-domain analysis section, the Fast Fourier Transform function (FFT) is used to convert the signal from the time domain to the frequency domain. After that, apply the appropriate function to achieve the multi-angle frequency-domain analysis in MATLAB according to the amplitude, phase, power and power spectral density of signal, and the analysis results are displayed in form of multiple spectrum. Then the user can visually analyze the signal characteristics through the spectrum graph. The essence of the Fourier transform is that, $f(x)$ is decomposed into a superposition of a number of frequencies of sine waves, so that the signal can be converted from the time domain to the frequency domain $[11,12]$.

\section{Analysis of shenyang subway noise based on MATLAB}

In China, the sound frequency range of low-frequency noise is defined as $20-200 \mathrm{~Hz}$. The more obvious influence on the human body is mainly distributed in $3-50 \mathrm{~Hz}$. Medical experts found that low-frequency noise on the human body may not only cause functional impairment, but also cause device quality damage and mental damage. In addition, four types of noise standards stipulate subway station noise standard is $70 \mathrm{~dB}$. On the basis of this, the noise of subway station and carriage is analyzed so as to find the main source of noise.

\subsection{Analysis of station noise signal with or without broadcast}

The station without train is analyzed, and it is divided into two cases such as the station with broadcast and without broadcast. Take FFT to transform the noise signals. The spectrum figure and decibel figure of station noise without broadcast are shown in fig. 1 and fig. 2 respectively.

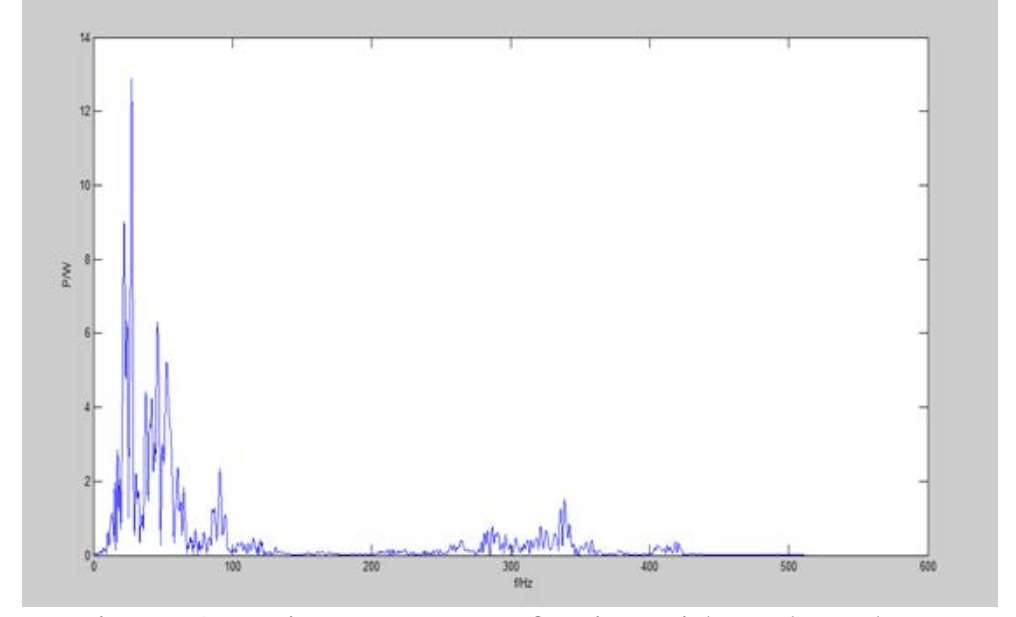

Figure 1: Noise spectrum of noise without broadcast 


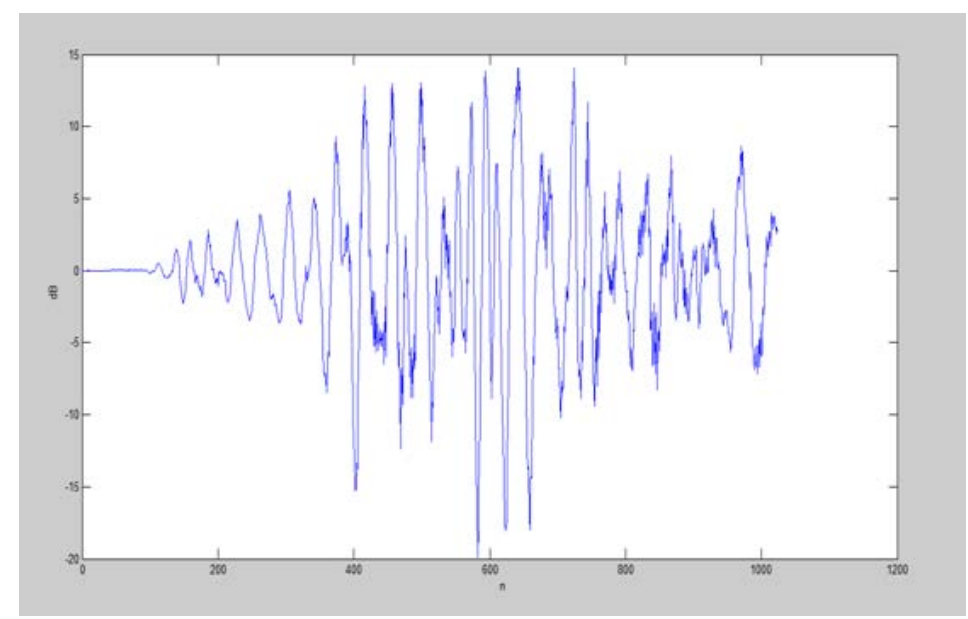

Figure 2: Noise decibel of noise without broadcast

From fig. 1 we can see that, the signal frequency is mainly in the range of $0-100 \mathrm{~Hz}$, and the most widespread is $27.5 \mathrm{~Hz}$. Fig. 2 shows that the noise is mainly around $15 \mathrm{~dB}$, and the maximum value is $14.035 \mathrm{~dB}$. The spectrum figure and decibel figure of station noise with broadcast are shown in fig. 3 and fig. 4 respectively.

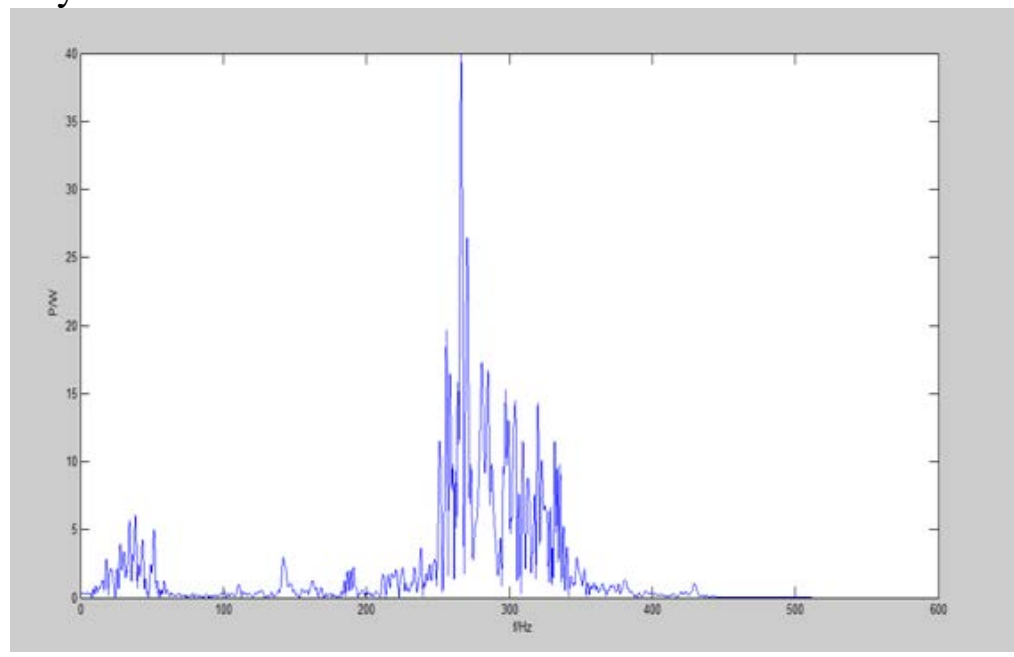

Figure 3: Noise spectrum of noise with broadcast

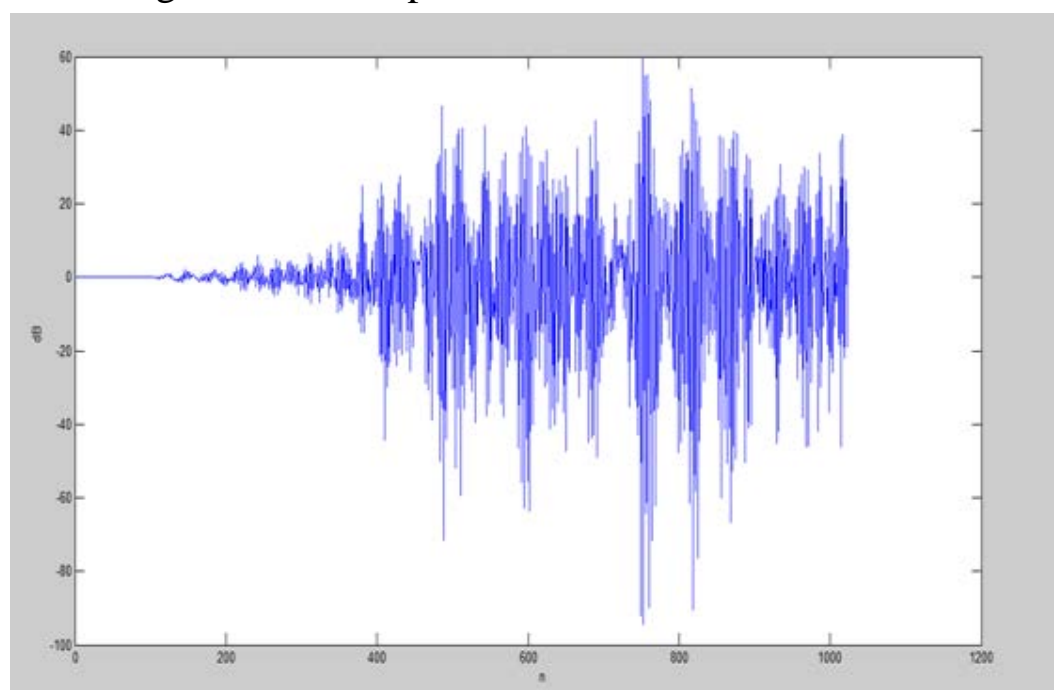

Figure 4:. Noise decibel of noise with broadcast

Seen from fig. 3, the signal frequency is mainly in the range of $250-300 \mathrm{~Hz}$, and the most widespread is $266 \mathrm{~Hz}$. Fig. 4 shows that the noise is mainly around $40 \mathrm{~dB}$, and the maximum value is $59 \mathrm{~dB}$. The maximum values and the standard deviation values are shown in Table 1. Can be analyzed, sound broadcasting is one of the sources of noise, and radio frequency and volume impact 
on human health is greater. It is a slight discomfort noise value. Moreover, the number and the time of broadcast have become more numerous. How to reconcile the contradictions of two areas will also need the efforts of to manage personnel and vehicle maintenance staff.

$\begin{array}{cccc}\begin{array}{c}\text { The most } \\ \text { widespread } \\ \text { frequency value } \\ \text { of noise with } \\ \text { broadcast }\end{array} & 27.5000 \mathrm{~Hz} & \begin{array}{c}\text { The most } \\ \text { widespread } \\ \text { frequency value } \\ \text { of noise }\end{array} & \begin{array}{c}266.4000 \mathrm{H} \\ \text { without } \\ \text { broadcast }\end{array} \\ \begin{array}{c}\text { The maximum } \\ \text { decibel value of } \\ \text { noise with } \\ \text { broadcast }\end{array} & 14.0350 \mathrm{~dB} & \begin{array}{c}\text { The maximum } \\ \text { decibel value of } \\ \text { noise without } \\ \text { broadcast }\end{array} & \\ \begin{array}{c}\text { The deviation } \\ \text { value compared } \\ \text { with standard } \\ \text { value (70dB) }\end{array} & -55.9650 \mathrm{~dB} & \begin{array}{c}\text { The deviation } \\ \text { value compared } \\ \text { with standard } \\ \text { value (70dB) }\end{array} & -10.1300 \mathrm{~d} \\ \text { B }\end{array}$

Table 1: The maximum and standard deviation values

\subsection{Analysis of station noise signal with or without train}

The station is continued to be analyzed, and it is divided into two cases such as the station with train and without train. The most widespread frequency values and the standard deviation values are shown in Table 2. From the study, we can see that, the signal frequency is mainly in the range of $0-100 \mathrm{~Hz}$ and $300-400 \mathrm{~Hz}$. Sound intensity is generally more than $50 \mathrm{~dB}$, and the maximum value is $90.3 \mathrm{~dB}$. The subway station noise standard is $70 \mathrm{~dB}$, and the noise generated by a train has exceeded the national standard. Compare with no train, it can be inferred that the main source of noise is the wheel-rail system noise, traction power system noise, brake system noise, aerodynamic noise and track structure noise.

$\begin{array}{cccc}\begin{array}{c}\text { The most } \\ \text { widespread } \\ \text { frequency value } \\ \text { of noise with } \\ \text { train }\end{array} & \begin{array}{c}27.5000 \mathrm{H} \\ \mathrm{z}\end{array} & \begin{array}{c}\text { The most } \\ \text { widespread } \\ \text { frequency value } \\ \text { of noise } \\ \text { without train }\end{array} & 333.8000 \mathrm{~Hz} \\ \begin{array}{c}\text { The maximum } \\ \text { decibel value of } \\ \text { noise with train }\end{array} & \begin{array}{c}14.0350 \mathrm{~d} \\ \text { B }\end{array} & \begin{array}{c}\text { The maximum } \\ \text { decibel value of } \\ \text { noise without } \\ \text { train }\end{array} & 90.3070 \mathrm{~dB} \\ \begin{array}{ccc}\text { The deviation } \\ \text { value compared } \\ \text { with standard } \\ \text { value (70dB) } \\ \text { Table 2: The maximum and standard deviation values }\end{array} & \begin{array}{c}\text { The deviation } \\ \text { value compared } \\ \text { with standard }\end{array} \\ \end{array}$

\subsection{Analysis of carriage noise signal when train stillness or running}

The carriage is analyzed, and it is divided into two cases such as the train stillness and running. The most widespread frequency values and the standard deviation values are shown in Table 3 . When the train is still, the most widespread frequency is $13.6 \mathrm{~Hz}$, and the maximum sound intensity is $2.18 \mathrm{~dB}$. When the train is running, the signal frequency is mainly in the range of $100-200 \mathrm{~Hz}$ and $300-500 \mathrm{~Hz}$, and the sound intensity is in the range of 2-8 dB. From the above, the noise level of running noise is slightly higher than the noise level of stationary. The main reason is that the running noise is generated by wheel-rail noise, machine noise, aerodynamic noise and arc noise. 


\section{Conclusion}

Subway noise had a significant impact on passengers and residents along the railroad. The noise sources are mainly stations broadcast, the wheel-rail noise, the noise generated by the mechanical movement, air conditioning noise and exhaust systems. In order to study the influence degree of these noise, time-domain and frequency-domain analysis are used for the subway station and subway carriage noise analysis in this paper. The processing function for powerful sound based on MATLAB can be inferred that subway noise sources are mainly broadcast noise or wheel-rail noise. This can provide the basis for subway noise prevention and control in the future, and will have huge social and economic benefits.

$\begin{array}{cccc}\begin{array}{c}\text { The most } \\ \text { widespread } \\ \text { frequency value } \\ \text { of noise when } \\ \text { stillness }\end{array} & 13.6000 \mathrm{~Hz} & \begin{array}{c}\text { The most } \\ \text { widespread } \\ \text { frequency value } \\ \text { of noise when } \\ \text { running }\end{array} & \begin{array}{c}382.8000 \mathrm{H} \\ \mathrm{z}\end{array} \\ \begin{array}{c}\text { The maximum } \\ \text { decibel value of } \\ \text { noise when } \\ \text { stillness }\end{array} & 2.1804 \mathrm{~dB} & \begin{array}{c}\text { The maximum } \\ \text { decibel value of } \\ \text { noise when } \\ \text { running }\end{array} & 6.5218 \mathrm{~dB} \\ \begin{array}{c}\text { The deviation } \\ \text { value compared } \\ \text { with standard } \\ \text { value (70dB) }\end{array} & -67.8196 \mathrm{~d} & \begin{array}{c}\text { The deviation } \\ \text { value compared } \\ \text { with standard } \\ \text { value (70dB) }\end{array} & -63.4782 \mathrm{~d} \\ & \mathrm{~B} & \mathrm{~B} \\ \end{array}$

Table 3: The maximum and standard deviation values

\section{References}

[1] Afeni T B \& Osasan S K. Assessment of noise and ground vibration induced during blasting operations in an open pit mine-a case study on ewekoro limestone quarry, nigeria. Mining Science \& Technology, pp. 420-424, 2009.

[2] Hood R A R. The calculation and assessment of ground-borne noise and perceptible vibration from trains in tunnel. Journal of Sound and Vibration, (01) . pp. 215-225, 1996.

[3] Neitzel, Richard, Gershon, Robyn R. M., Zeltser, Marina, Canton, Allison \& Akram, Muhammad. Noise levels associated with New York city's mass transit systems. American Journal of Public Health, 99 (8) . pp. 1393, 2009.

[4] Daoming Shen, Laidong Zhang \& Songtao Xue. Experimental investigation on characteristics and evaluation indexes of ground-borne noise induced by subway. Journal of Chongqing Jianzhu University, 35 (4). 2013.

[5] Canping Zhou, Chong He \& Zaixiu Jiang. Study on the method of evaluation and it's limited value oil environment influence to noise caused by urban railway traffic.[J]. Environmental Monitoring in China, 25 (4). 2009.

[6] Jiahua Liu \& Songliang Lian. Vibration and noise of the urban rail transit. Journal of Traffic and Transportation Engineering, 2 (1). 2002.

[7] Xiaopai Zhang, Yan Liu \& Zhifang, Zhong. Characteristics of noise in subway cars. Noise and Vibration Control, 30 (2). 2010.

[8] M Szwarc, B Kostek \& J Kotus. Problems of railway noise-a case study. International Journal of Occupational Safety and Ergonomics (JOSE), 17(3), pp. 319-325, 2011.

[9] Shuo Huang, Wenyang Duan \& Qingwei Ma. An approximation to energy dissipation in time domain simulation of sloshing waves based on linear potential theory. China Ocean Engineering, 25(2). 2011.

[10] Birger Hjørland. Domain analysis in information science: eleven approaches - traditional as 
well as innovative. Journal of Documentation, 58 (4) . pp. 422 - 462, 2002.

[11] Ke Li, Chunping Hou, Yonghong Hou \& Jinlin Fu. New cooperative frequency domain differential modulation and demodulation. Journal of Systems Engineering and Electronics, 22(6). 2011.

[12] Wang Wen-dong, Zhang Gen-yao \& Wang Wen-fa. The digital image process in frequency area. Journal of xi'an university engineering science and technology, 20(4). 2006. 